\title{
Risk monitoring for the city in geological hazards conditions
}

\author{
Alexander Ginzburg, ${ }^{1, *}$, Sergey Kachanov ${ }^{2,3}$ and Gennagij Nigmetov $^{2}$ \\ ${ }^{1}$ Moscow State University of Civil Engineering, 129337, 26, Yaroslavskoye Shosse, Moscow, Russian \\ Federation \\ ${ }^{2}$ All-Russia Scientific Research Institute on Problems of Civil Defense and Emergency Situations \\ (federal scientific and high-tech solutions center), 121352,7, Davidkovskaya str., Moscow, Russian \\ Federation \\ ${ }^{3}$ Moscow Institute of Physics and Technology, 141700, 9, Institutskiy per., Dolgoprudny, Moscow Region, \\ Russian Federation
}

\begin{abstract}
Article looks on the main risks of geological hazards for potentially dangerous, unique and technically complex facilities and given proposals for their monitoring
\end{abstract}

\section{Introduction}

Nowadays, the development of modern socio - economic system and growth of urban areas leads to the fact that more and more potentially dangerous, unique and technically complex facilities are located in geologically hazardous areas. In addition, soil mass that is in state of relative equilibrium before construction, can exit this state of equilibrium due to effects dynamic and static loads from construction and transport objects, located nearby. Loss of equilibrium state and stability of the soil mass leads to subsidence, landslides, disruption of hydrological regimes, suffusion, karstic phenomena, excessive vibration, and, as a consequence, to an increased risk of collapse of buildings and structures .

\section{Main part}

Specialists of VNII GOChS designed technology for dynamic-geophysical monitoring of the "soil-structure" system that lets you see the possible changes in the system according to the impact of external factors.

Examples of implementing of this technology by VNII GOChS on the objects with geological hazards are:

-monitoring of residential buildings in Kaliningrad city with tilts and deformation cracks caused by exposure to vibration during the bank protection works on the embankment of the river;

-monitoring of the facilities during subsidence of foundation slabs against each other during construction of Olympic facilities in Imereti Valley in Adler city;

\footnotetext{
* Corresponding author: ginAV@mgsu.ru
} 
-monitoring of the school in Moscow city, affected by the influence of excessive vibration from a nearby subway tunnel;

-monitoring of the building with deformation cracks caused by construction of a nearby facility with deep foundations;

-monitoring of the slope in the zone of sliding roadway in Ulyanovsk, caused by the influence of inefficient drainage, excessive vibration from passing railway transport and heavy vehicles (Fig.1).

We have accumulated many of such examples in our practice. In this regard, besides automated monitoring of engineering structures of buildings in geologically hazardous areas, we advise to monitor geological hazards, which may cause damage to the objects located in risk areas of such hazards. Such monitoring should be carried out at the stage of research and construction, and after the completion of construction in potentially dangerous areas.

The technology of complex dynamics and geophysical monitoring consists of the measurement and analysis system (Fig. 2 and Fig. 3) that is installed in the zone of possible geological hazards and consisting of:

- a computer with specialized software that allows to receive and, according to specific criteria, to process and analyze digital data from sensors installed in a controlled area;

- multi-channel analog-to-digital converter (ADC);

- three-way acceleration sensors, tilt sensors, water level sensors and soil pore pressure sensor;

- $\quad$ radio channel or cable transmission system from the sensors to the ADC.

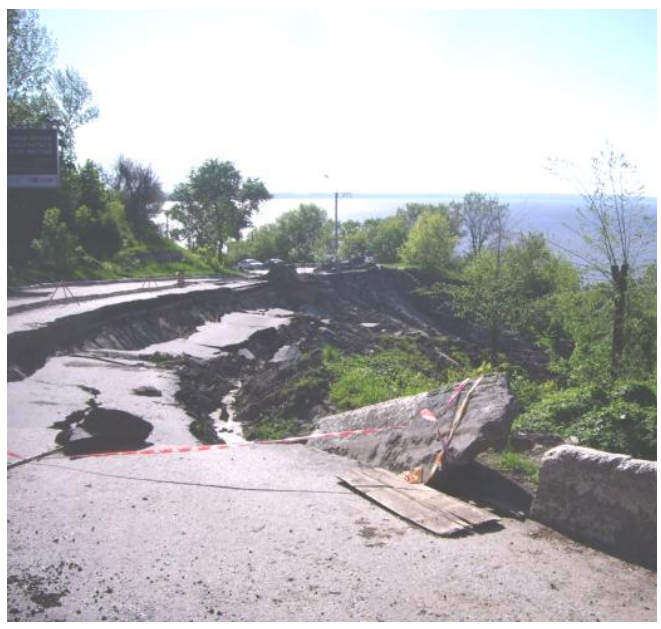

Fig.1. Sliding roadway in Ulyanovsk, caused by the influence of inefficient drainage, excessive vibration from passing railway transport and heavy vehicles

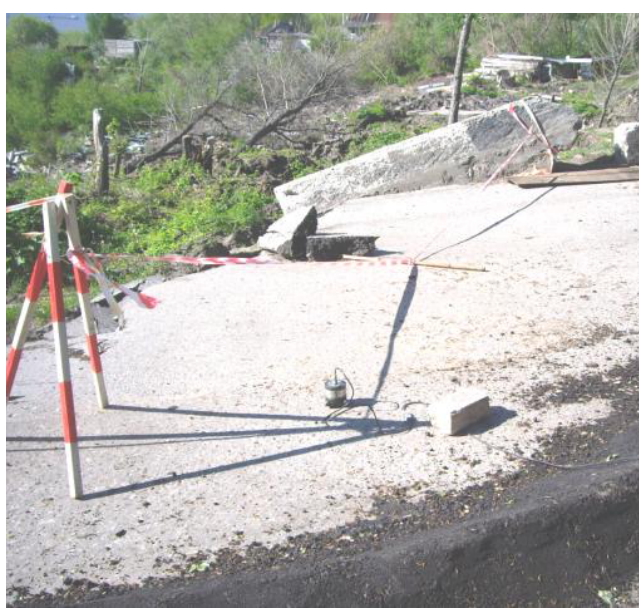

Fig.2. Installation of a mobile dynamicgeophysical monitoring system in landslide hazardous road section in Ulyanovsk.

Criteria, developed with participation of the authors, for assessing stability of soil mass with dynamic-geophysical monitoring results, make it possible to determine the onset of unstable soil equilibrium at an early stage from a day to a few hours. Oscillations are sensitive parameters for stiffness of structural systems. Oscillations in soil mass, as well as in structures depend on its mass and stiffness.

Solution of the differential equation that describes the oscillations of an object with length $l$ (for example a beam) appears as follows [1-8]: 


$$
\mathrm{T}_{1}=\frac{l^{2}}{\pi^{2}} \sqrt{\frac{m}{E J}}
$$

where $T_{1}$ is a period of oscillation of the object (s); $l$ is a length of an object $(\mathrm{m}) ; \mathrm{m}$ is a mass of an object $(\mathrm{kg})$; $\mathrm{E}$ is a module of elasticity $\left(\mathrm{N} / \mathrm{m}^{2}\right)$ and $\mathrm{J}$ is a moment of inertia of an object $\left(\mathrm{m}^{4}\right)$.

Equation for soil mass, relating its oscillations with geometrical, physical, and mechanical properties, can be represented as follows:

$$
T_{1}=2.63 * H \sqrt{\frac{\rho}{G}},
$$

where $\rho$ is a density of the considered soil mass unit; $\mathrm{G}$ is a shear modulus of the soil mass and $H$ is a height of the soil mass unit.

Therefore, by controlling the oscillation period of an object or soil mass, we can control rigidity including the degree of water content of the soil mass.

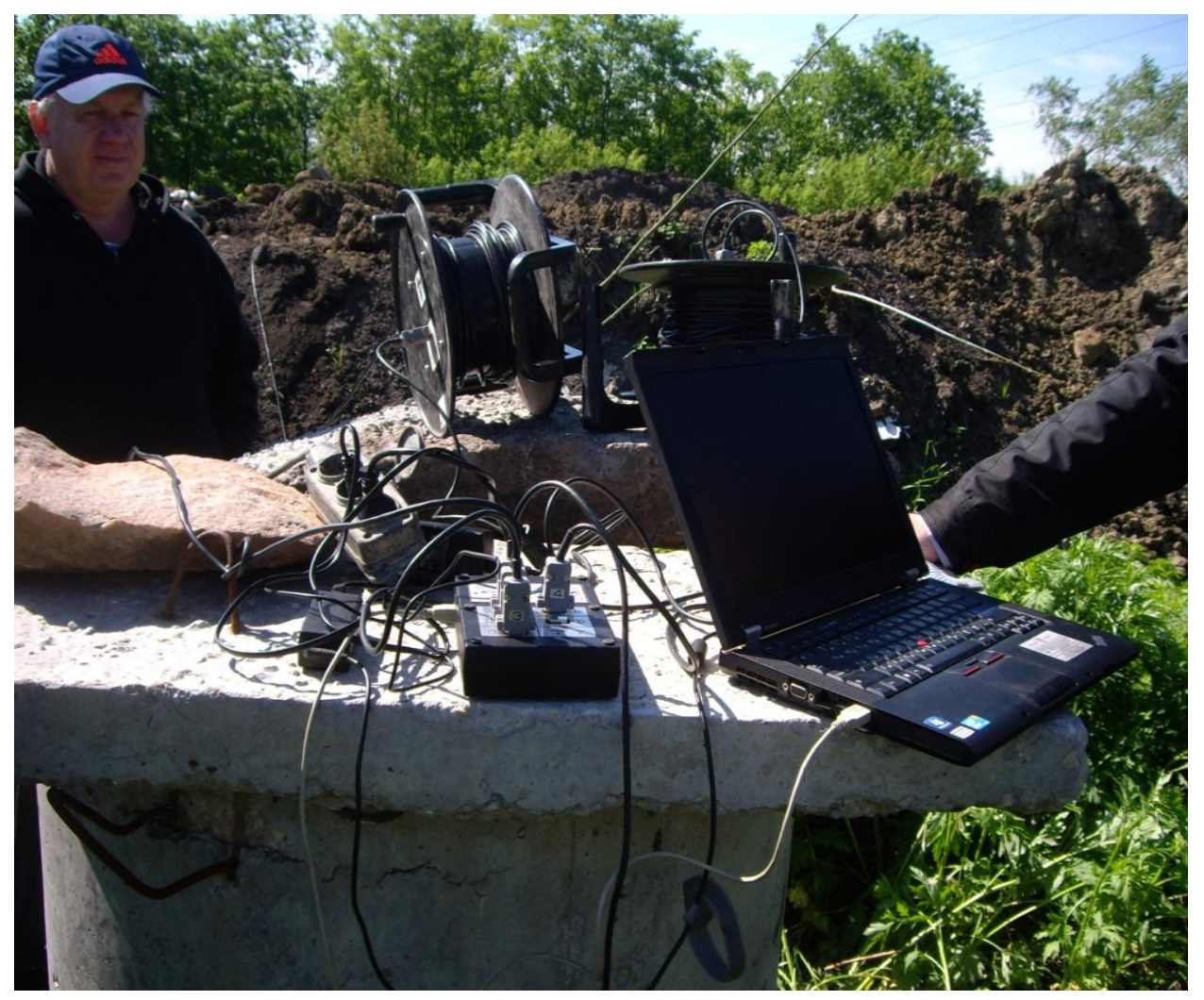

Fig.3. Data acquisition position for dynamic-geophysical tests of the impact of dynamic and baseline loads on soil mass in the area of the construction site of residential complex and the road at the site of landslide. 
Table 1.Results of dynamic-geophysical tests of the soil mass with different kinds of dynamic effects.

\begin{tabular}{|c|c|c|c|}
\hline $\begin{array}{l}\text { Object and types of } \\
\text { measurements }\end{array}$ & $\mathbf{A}_{\mathrm{x}}, \mathbf{m} / \mathbf{s}^{2}$ & $\mathbf{A}_{\mathbf{y}}, \mathbf{m} / \mathbf{s}^{2}$ & $\mathbf{A}_{\mathrm{z}}, \mathbf{m} / \mathbf{s}^{2}$ \\
\hline $\begin{array}{l}\text { Soil mass, baseline } \\
\text { effects }\end{array}$ & $\begin{array}{l}\mathbf{0 , 0 0 3} \\
0,015 \\
0,03 \\
0,004\end{array}$ & $\begin{array}{l}\mathbf{0 , 0 0 3} \\
0,01 \\
0,01 \\
0,004\end{array}$ & $\begin{array}{l}\mathbf{0 , 0 0 4} \\
0,005 \\
0,005 \\
0,003\end{array}$ \\
\hline Soil mass, trams passage & $\begin{array}{l}\mathbf{0 , 0 0 4} \\
0,01 \\
0,03 \\
0,008 \\
\end{array}$ & $\begin{array}{l}\mathbf{0 , 0 0 4} \\
0,01 \\
0,01 \\
0,003 \\
\end{array}$ & $\begin{array}{l}\mathbf{0 , 0 0 4} \\
0,02 \\
0,005 \\
0,004 \\
\end{array}$ \\
\hline $\begin{array}{l}\text { Soil mass, passage of } 35 \mathrm{t} \\
\text { truck }\end{array}$ & $\begin{array}{l}\mathbf{0 , 0 1} \\
0,042 \\
0,03 \\
0,006\end{array}$ & $\begin{array}{l}\mathbf{0 , 0 1 7} \\
0,05 \\
0,02 \\
0,006\end{array}$ & $\begin{array}{l}\mathbf{0 , 0 1} \\
0,09 \\
0,005 \\
0,002\end{array}$ \\
\hline $\begin{array}{l}\text { Soil mass, pile driving } \\
\text { with } 2.5 \mathrm{t} \text { diesel hammer }\end{array}$ & $\begin{array}{l}\mathbf{0 , 0 0 5} \\
0,022 \\
0,022 \\
0,15\end{array}$ & $\begin{array}{l}\mathbf{0 , 0 0 4} \\
0,02 \\
0,015 \\
0,3\end{array}$ & $\begin{array}{l}\mathbf{0 , 0 0 5} \\
0,01 \\
0,01 \\
0,2\end{array}$ \\
\hline $\begin{array}{l}\text { Soil mass, pile driving } \\
\text { with } 5 \mathrm{t} \text { hydraulic device }\end{array}$ & $\begin{array}{l}\mathbf{0 , 0 0 6} \\
0,045 \\
0,03 \\
0,52\end{array}$ & $\begin{array}{l}\mathbf{0 , 0 0 4 1} \\
0,03 \\
0,03 \\
1,25\end{array}$ & $\begin{array}{l}\mathbf{0 , 0 0 5 2} \\
0,015 \\
0,01 \\
0,6\end{array}$ \\
\hline Soil mass, passing train & $\begin{array}{l}\mathbf{0 , 0 2} \\
0,01 \\
0,02\end{array}$ & $\begin{array}{l}\mathbf{0 , 0 0 5} \\
0,01 \\
0,015\end{array}$ & $\begin{array}{l}\mathbf{0 , 0 0 5} \\
0,0075 \\
0,0075\end{array}$ \\
\hline
\end{tabular}

Table 2. Period of natural oscillations of the soil mass in wet state and after extensive drainage works:

\begin{tabular}{|l|l|c|c|c|}
\hline № & $\begin{array}{l}\text { Condition of the soil mass } \\
\text { during } \\
\text { geophysical } \\
\text { measurements. }\end{array}$ & $\mathbf{T}_{\mathbf{x}}, \mathbf{s .}$ & $\mathbf{T}_{\mathbf{y}}, \mathbf{s .}$ & $\mathbf{T}_{\mathbf{z}}, \mathbf{s .}$ \\
\hline 1 & Heavily watered & 0,078 & 0,078 & 0,078 \\
\hline 2 & $\begin{array}{l}\text { After drainage instalment, } \\
\text { soil moderately moist }\end{array}$ & $\begin{array}{l}0,05 \\
\text { Shifted to the } \\
\text { high frequency } \\
\text { area }\end{array}$ & $\begin{array}{l}\text { Shifted to the } \\
\text { high frequency } \\
\text { area }\end{array}$ & $\begin{array}{l}\text { Shifted to the high } \\
\text { frequency area }\end{array}$ \\
\hline
\end{tabular}

Analysis of the data presented in Table №1 shows that the amplitude of accelerations of landslide slope caused by the passage of railway freight train, exceeds baseline fluctuations of the slope by $\mathbf{6 . 6}$ times, the passage of a heavy trucks increases amplitude of accelerations of the slope exceeds by $\mathbf{3 . 3}$ times. Slope oscillation periods during the passage of trains and trucks shifts to the resonance frequencies $(0.1-0.2) \mathrm{s}$, which increases the risk of loss of stability of slope soil mass.

Results of comparison of the dynamic-geophysical parameters of moistened soil mass (Table 2) with the soils with installed drainage system, and with reducing the groundwater level at landslide-prone area show that in all axes of measurement periods of natural oscillations shifted to higher frequencies.

These comparisons show how sensitive dynamic-geophysical parameters are to the change of the soil state. Effectively performed work on lowering the groundwater level 
increased stiffness of the soil mass, reduced deformability processes and increased stability of landslide-prone slopes.

Measurement results show that the greatest accelerations and therefore greatest displacements of the soil mass-produce dynamic loads generated by the movement of freight trains and heavy trucks. Maximum acceleration occurs in the X-axis (along the river Volga, maximum soil displacements occurred in this direction).

Accelerations occurred due to driving of foundation piles during construction of the building on the top of the slope are registered in the area of the landslide at the baseline level and could not be the cause of this landslide.

The main cause of the landslide was a strong hydration of the soil mass, which led to its oscillations with a period of natural oscillations equal to 0,078 in all axes, and caused by resonant dynamic effects of passing trains and heavy trucks.

\section{Conclusions}

Example, presented in the article, shows that the decrease of the landslide hazard of soil mass on slope can be provided by:

1. Installment of drainage ans storm-water removal systems to ensure effective withdrawal of groundwater;

2. Control of the soil mass state for the timely definition of dynamic-geophysical parameters and for elimination of resonance phenomena from dynamic effects;

3. Comprehensive monitoring of "soil-structure" systems.

Our experience shows that application of such complex monitoring systems can provide timely warning of the urban population about the risk of geological hazard. Monitoring measurements will allow to ensure the correct choice of rational engineering measures to improve the stability of the "soil-structure" system on the design stage, and will allow to ensure monitoring of the effectiveness of the work on the operational phase.

\section{References}

1. A.Ginzburg, S. Kachanov, IJAER 10(20), 40869-40872 (2015)

2. A.Ginzburg, S. Kachanov, IJAER 11(3), 1660-1665 (2016)

3. A.Ginzburg, A. Ryzhkova, IJAER 10(21), 41828-41830 (2015)

4. A. Volkov, AMM 838-841, 2973 (2014)

5. A. Volkov, V. Chulkov, R. Kazaryan, R. Gazaryan, AMM 584-586, 2685 (2014)

6. G. Nigmetov, M. Chubakov, Seysmostoykoe stroitel'stvo 4, 51-55 (2011)

7. G.M. Nigmetov, Cataloque of seismoforecasting research, 147-154 (2009)

8. G.M. Nigmetov, Cataloque of seismoforecasting research, 99-104 (2010) 